\title{
Biosynthesis and Characterisation of Silver Nanoparticles using Leaf Extract of Achras sapota l. for its Antimicrobial Activity
}

\author{
Maphibanri Maring*1, Akila Elias', V. B. Narayanaswamy ${ }^{1}$ \\ ${ }^{1}$ Department of Pharmacognosy, RR College of Pharmacy, Bangalore, Karnataka, India
}

\section{Article Info}

Volume 7, Issue 5

Page Number: 246-256

Publication Issue :

September-October-2020

\section{Article History}

Accepted : 03 Oct 2020

Published : 14 Oct 2020

\section{ABSTRACT}

Nanotechnology is a field that is rapidly growing, making an impact in all spheres of human life. In the current study, silver nanoparticles were synthesized using the ethanolic leaf extract of Achras sapota. Characterization was carried out using UV-Visible spectroscopy, FTIR, XRD, SEM and TEM. The formation of AgNPs was confirmed through UV-Visible spectroscopy by the colour change. Based on the XRD pattern, the crystalline property of the AgNPs was established. The functional group present in the ethanolic leaf extract of Achras sapota is responsible for the reduction of the $\mathrm{Ag}^{+}$ion which was studied through FTIR. From the SEM and TEM analysis, it was found that the formed nanoparticles are spherical in shape and nano in size. The biosynthesized AgNPs was evaluated for its antimicrobial activity against gram positive bacteria $(S$. aureus and $L$. bacillus) and gram negative bacteria ( $E$. coli and $P$. aeruginosa) using disc diffusion for preliminary screening of antimicrobial activity and dilution method for evaluation of antibacterial effectiveness and effect of silver nanoparticles on bacterial growth and it was found to exhibit potential antimicrobial activity. The biosynthesized AgNPs was found to be efficient in terms of reaction time as well as stability, ecofriendly and cost effective.

Keywords : Nanotechnology, Green synthesis, Silver nanoparticles, Antimicrobial activity.

\section{INTRODUCTION}

Nanotechnology may be outlined as the manipulation of matter through certain processes to make materials with specific properties, which may be employed in specific applications. A nanoparticle is a microscopic particle that has atleast one dimension less than a hundred nanometers in size. ${ }^{1}$ Materials within the nano dimensions (1-100 nm) have outstanding distinction in the properties compared to a similar material in the bulk. These distinction be the physical and structural properties of atoms, molecules and bulk materials of the component because of distinction in physico chemical properties and surface to volume quantitative relation. ${ }^{2}$ Owing to the interest and importance of nanoparticles several researchers have centered on the synthesis of nanoparticles using 
chemical and physicals ways, however unfortunately they are quite costly and probably dangerous to the surroundings that involve use of harmful and threatening chemicals that are liable for numerous biological risk. ${ }^{3}$ A wide selection of biological resources like micro organisms (bacteria, yeast, fungi, algae, and viruses) and plants are often used for nanoparticle synthesis. The major drawback of microbe-mediated nanoparticle synthesis is that the obligatory constraint of antiseptic conditions, which requires trained workers and raises the scaling value. Of these reasons, at the side of the straight forward handiness of plants in nature, make them more preferred biological resources than microbes. ${ }^{1}$ The synthesis of nanoparticles using plant extract provides advancement over different ways because it is easy, one step, price effective, surroundings friendly and comparatively reproducible results. $^{3}$ There are differing types of nanomaterials. Depending on dimensions they are being classified into 4 types: one dimensional, two dimensional, three dimensional nanostructures. Nanomaterials are a product of inorganic or carbon (fullerenes, nanotubes, etc.) based materials. The latter, embrace metal oxides (iron oxide, cerium oxide, zinc oxide, titanium oxide, etc.) metals (iron, silver, gold, etc.) and quantum dots (cadmium selenide and cadmium sulfide). ${ }^{4}$ The nanoparticles used for all same procedures, the metallic nanoparticles thought-about because the most promising as they contain exceptional antibacterial properties that is of interest for researchers because of growing microbial resistance against metal ions, antibiotics and also the development of resistant strains. Among all the metallic nanoparticles, silver nanoparticles are an arch product as a result of their distinctive properties like chemical stability, sensible conduction, catalytic and most vital antibacterial, antiviral, antifungal additionally to anti inflammatory properties. ${ }^{5}$

\section{METHODS AND MATERIAL}

\subsection{Plant material collection and identification}

The plant Achras sapota leaf was collected from the surrounding areas of Bangalore. It was dried under shade and made into coarse powder. The plant was then identified and authenticated by Assistant Prof (Dr) K. Madhava Chetty, Department of Botany, Shree Vinkateswara University Tirupati Chittur district, Andhra Pradesh.

\subsection{Phytochemical studies ${ }^{6,7}$}

Phytochemical screening was carried out by the methods referred from text book authored Pulok Mukherjee and Kokate.

\subsection{Determination of total phenolic content (TPC)}

Total phenolic compounds were determined by using Folin-Ciocalteu method.

\subsection{Synthesis of nanoparticles}

\section{- Selection of leaf extract ${ }^{8}$}

Achras sapota ethanolic leaf extract was selected for the synthesis of silver nanoparticles because of its high phenolic content.

\section{- Biosynthesis of Silver Nanoparticles ${ }^{8}$}

For biosynthesis of silver nanoparticles, $5 \mathrm{ml}$ of the prepared ethanolic leaf extract of Achras sapota was added to $95 \mathrm{ml}$ of $1 \mathrm{mM}$ aqueous silver nitrate solution and stirred properly. The visual colour change in the reaction mixture from colorless to dark brown should be observed and the reaction mixture was then incubated at room temperature for a period of $24 \mathrm{hrs}$ for the complete reduction of silver ions to silver nanoparticles. The formation of silver nanoparticles was confirmed by UV-Visible spectroscopy. After the synthesis of AgNPs, the solution containing nanoparticles was centrifuged at 
$8000 \mathrm{rpm}$ for $10 \mathrm{mins}$ to separate silver nanoparticles from other composition of solution and the deposit was prepared for relevant analysis. The dried AgNPs were kept in microtube for further studies.

\subsection{Characterisation of silver nanoparticles ${ }^{9,2}$}

The formation of silver nanoparticles using plant extract was monitored by various analytical techniques like UV-Vis spectroscopy, FTIR, XRD, SEM and TEM.

\subsection{Antimicrobial activity of the biosynthesized silver nanoparticles}

\section{- Preliminary test for antibacterial activity ${ }^{10}$}

The antimicrobial activity of AgNPs was evaluated against gram negative microorganism (Escherichia coli and Pseudomonas aeruginosa) and gram positive microorganisms (Staphylococcus aureus and Lacto bacillus) by cup diffusion method. Approximately $10^{6}$ colony-forming units (CFU) of the microorganisms were inoculated on Luria Broth (LB) agar plate and then $50 \mu \mathrm{g} / \mathrm{ml}$ concentrations of AgNPs were loaded in the wells present in the LB agar plate. A reaction mixture lacking AgNPs and Achras sapota leaf extract were loaded in the wells in the LB plate and cultured under the same condition as the control test. Ampicillin was the standard drug being used. All the $\mathrm{LB}$ plates were incubated in the incubator at $37^{\circ} \mathrm{C}$ overnight. After incubation period, the plates were observed for the zone of inhibition.

- Evaluation of antibacterial effectiveness using Minimum Inhibitory Concentration method ${ }^{11}$

The antimicrobial effectiveness of AgNPs were evaluated by Minimum Inhibitory Concentration (MIC) which was determined by broth dilution method against microorganism including gram negative (Escherichia coli and Pseudomonas aeruginosa) and gram positive (Staphylococcus aureus and Lacto bacillus). In $5 \mathrm{ml} \mathrm{LB}$ broth, $100 \mu \mathrm{L}$ of AgNPs from different concentrations (50, 25, 10, 5, 1, $0.5,0.25, \quad 0 \mu \mathrm{g} / \mathrm{ml})$ and $100 \mu \mathrm{L}$ of each test microorganisms were added. The cultures were then incubated at $37^{\circ} \mathrm{C}$ for 24 hours with shaking. AgNPs with inoculum in Luria broth media were used as positive control. The results were then monitored by measuring the mean optical density OD at $600 \mathrm{~nm}$.

\section{- Effect of AgNPs on bacterial growth ${ }^{11}$}

To determine the growth curve in the presence of silver nanoparticles, Escherichia coli, Pseudomonas aeruginosa, Staphylococcus aureus and Lacto bacillus were grown in the liquid LB medium. These microorganisms were activated by culturing $100 \mu \mathrm{L}$ of each in $10 \mathrm{ml} \mathrm{LB}$ medium, and then incubated it at $37^{\circ} \mathrm{C}$ for 24 hours with shaking at $150 \mathrm{rpm}$. Then, in $10 \mathrm{ml} \mathrm{LB}$ broth, $100 \mu \mathrm{L}$ of AgNPs from different concentrations $(50,25,10,5,1,0.5,0.25,0 \mu \mathrm{g} / \mathrm{ml})$ and $100 \mu \mathrm{L}$ of each microorganism were added. The microbial growth was then monitored by measuring the optical density (OD) at $600 \mathrm{~nm}$.

\section{RESULTS AND DISCUSSION}

\subsection{Phytochemical studies}

The preliminary screening for the Achras sapota leaf using four different extracts (Petroleum ether, chloroform, ethanol and water) was carried out and it was found to contain alkaloids, carbohydrates, flavonoids, glycosides, phenol, protein, steroids and tannins.

\subsection{Total phenolic content (Table 1)}

Phenol was found to be absent in the petroleum ether extract of Achras sapota leaf. So, the total phenolic content was carried out for only three extracts.

Table 1: Total phenolic content 


\begin{tabular}{|c|c|}
\hline Solvents & Total phenols (mg GAE/g) \\
\hline Chloroform & $1.29 \pm 0.07$ \\
\hline Ethanol & $22.40 \pm 0.05$ \\
\hline Water & $10.32 \pm 0.08$ \\
\hline
\end{tabular}

\subsection{Synthesis of silver nanoparticles}

The formation of AgNPs by the reduction of silver nitrate was indicated by the change in colour of the reaction mixture to dark brown colour (Figure 1) within 24 hours. The appearance of dark brown color within 24 hours of incubation confirms the reduction of $\mathrm{AgNO}_{3}$ into AgNPs. After 24 hours, no change in the colour is observed which indicates that the AgNPs synthesis process was completed. On the other hand, no change in colour was observed in the control solution that contained only $1 \mathrm{mM} \mathrm{AgNO}_{3}$ solution and had been kept under the same conditions as that in the other flask (Figure 1).

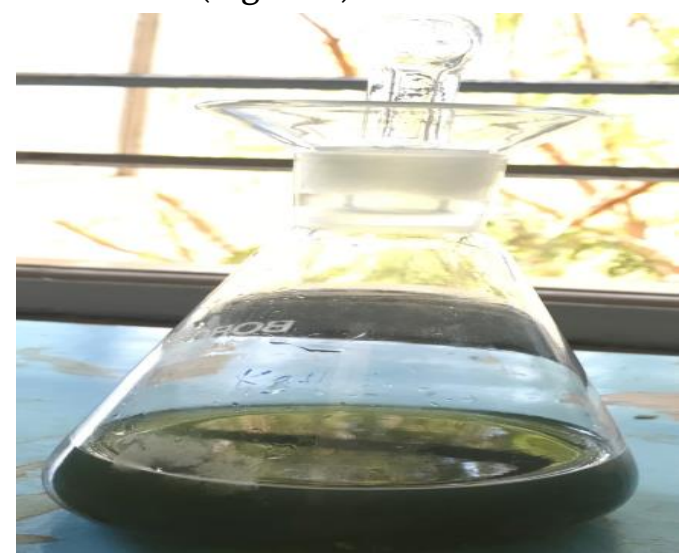

A. Achras sapota leaf extract

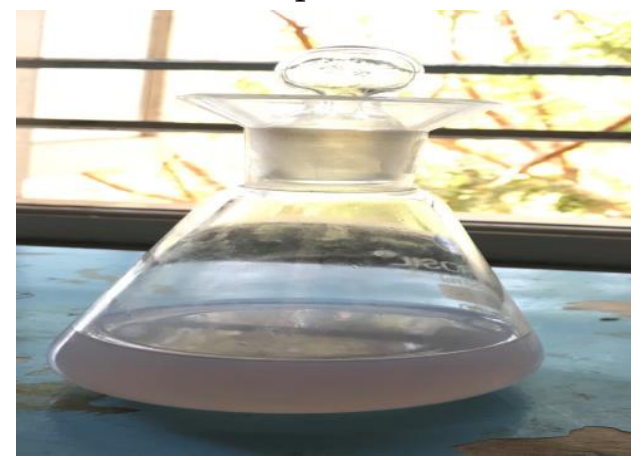

B. AgNO3 solution (control)

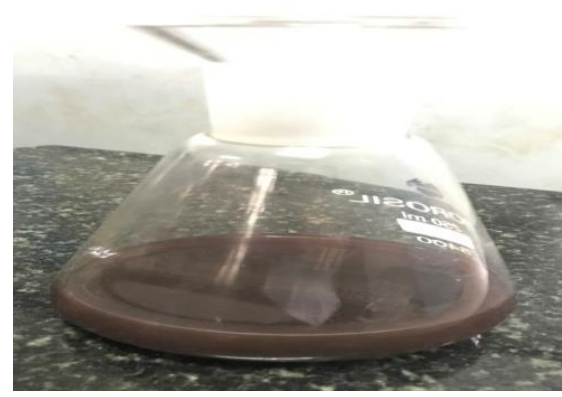

C. AgNPs

Figure 1: Silver nanoparticles formation.

3.4 Characterisation of biosynthesized silver nanoparticles

\section{- UV-Visible spectral analysis}

The Surface Plasmon Resonance (SPR) band of silver nanoparticles occurs at $400-450 \mathrm{~nm}$. In this study, the synthesized AgNPs using ethanolic leaf extract of Achras sapota showed SPR band between $400-450 \mathrm{~nm}$ which confirms the formation of silver nanoparticles (Figure 2). An early report suggests that single SPR band in the absorption spectra indicates spherical metal nanoparticles and two or more SPR bands indicate anisotropic particles. ${ }^{12}$ With reference to that AgNPs prepared by using ethanolic leaf extract of Achras sapota showed single and sharp SPR band which indicate that the nanoparticle is spherical in shape.

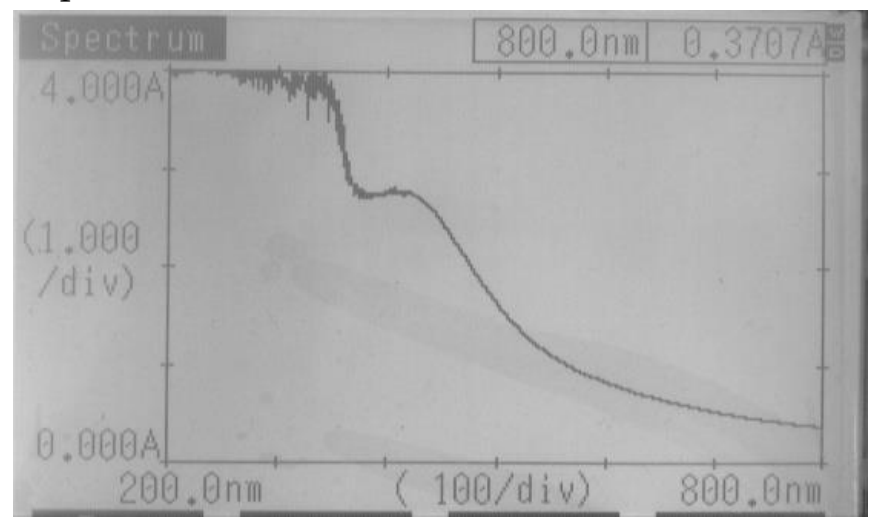

Figure 2: UV-Vis spectra for AgNPs 
- Fourier Transform Infrared Spectroscopy

The representative ATR FTIR spectra of the ethanolic leaf extract of Achras sapota and the stabilized silver nanoparticles were shown in Figure 3 and 4 . It can be seen that, in contrast to the ethanolic extract of Achras sapota, the stabilized silver nanoparticles show significant changes in their respective vibrational spectra. The ethanolic leaf extract of Achras sapota showed intense peaks at $3270.30 \mathrm{~cm}^{-1}$ and $1633.01 \mathrm{~cm}^{-1}$ (Figure 3). In stabilized silver nanoparticles the strong bands were observed at $3308.81 \mathrm{~cm}-1,1637.29 \mathrm{~cm}^{-1}, 1437.62 \mathrm{~cm}^{-1}, 1312.11$ $\mathrm{cm}^{-1}, 1140.97 \mathrm{~cm}^{-1}, 986.94 \mathrm{~cm}^{-1}, 901.37 \mathrm{~cm}^{-1}$ (Figure 4). In the Plant extract the peak was broad and blends, but after encapsulation of nanoparticles the peak was narrow and sharper. The absorption peak at 3270.30 $\mathrm{cm}^{-1}$ observed in control extract, is due to $\mathrm{OH}$ stretching vibration, $1633.01 \mathrm{~cm}^{-1}$ is due to $\mathrm{C}=\mathrm{O}$ stretching, which indicates that the control extract may have the phenolic substances. These structural changes indicated that the reduction and stabilization of silver nanoparticles proceed via the coordination between the phenolic substances of the plant extracts with the silver ions. The FTIR studies have confirmed the fact that the Phenolic group has the stronger ability to bind metal indicating that the phenolic constituents could possibly form a layer covering the metal nanoparticles (i.e., capping of silver nanoparticles) to prevent agglomeration and thereby stabilize the medium.

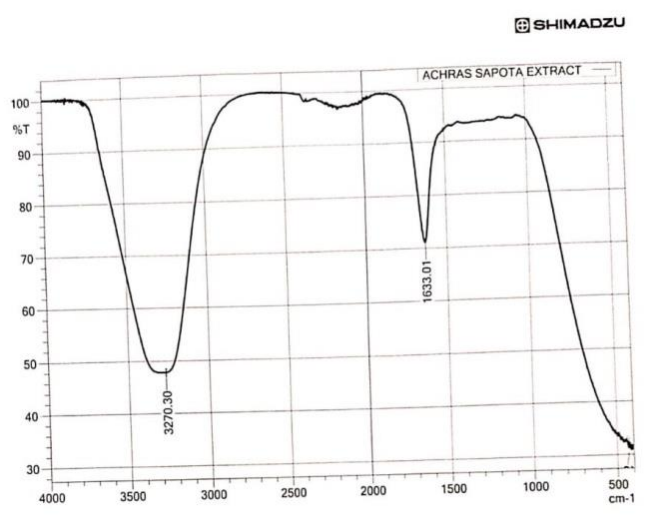

Figure 3
ФSHIMADZU

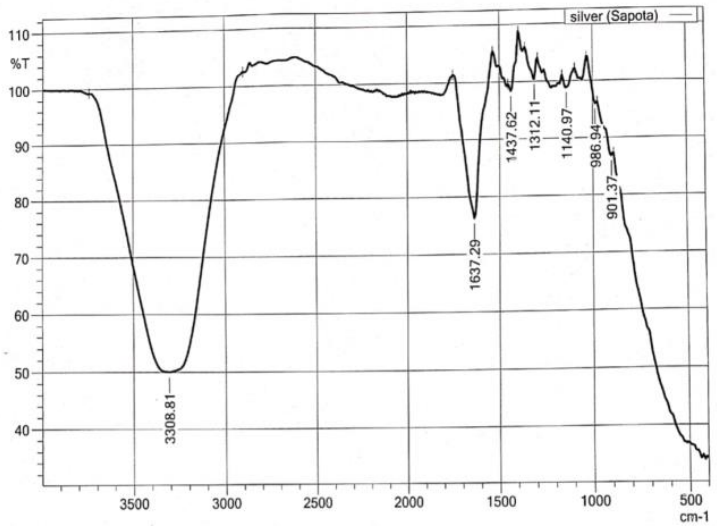

Figure 4

Figure 3 and 4: FTIR Spectra of ethanolic leaf extract of Achras sapota and AgNPs synthesized by Achras sapota respectively

\section{- X-ray Diffractometry}

The crystalline nature of silver nanoparticles was confirmed from X-ray diffraction. XRD analysis shows that XRD pattern of the dried nanoparticles obtained from colloid samples. Three peaks were observed at $38.16^{\circ}, 44.43^{\circ}$ and $24.26^{\circ}$ in the $2 \theta$ range $10-80^{\circ}$ for silver nanoparticles (Figures 5). These Braggs reflections clearly indicated that presence of (2.35646), (2.03738) and (3.66582) sets of lattice planes and further on the basis that they can be indexed as face centered-cubic (FCC) structure of silver. The observed peak broadening and noise were probably macromolecules present in the plant extract which may be responsible for the reduction of silver ions. Hence XRD pattern thus clearly illustrated that the silver nanoparticles formed in this present synthesis are crystalline in nature. In addition to the Bragg peaks representative of FCC silver nanocrystals; additional as yet unassigned peaks are also observed suggesting that the crystallization of bio-organic phase occurs on the surface of the Silver nanoparticles. 


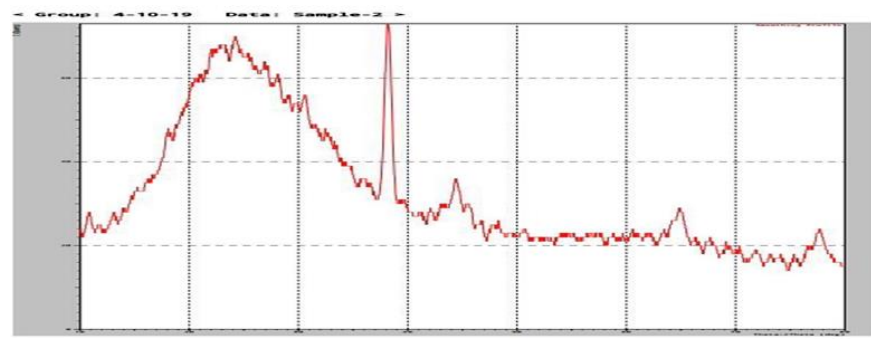

Figure 5: XRD pattern of AgNPs synthesized by Achras sapota

- Scanning Electron Microscopy

SEM results suggest that synthesized AgNPs are present in the nanometer range and the particles are monodispersed (Figure 6). White particles were observed for AgNPs at different magnifications. The overall morphology of most of AgNPs may be described as irregular, some possess spherical shape.

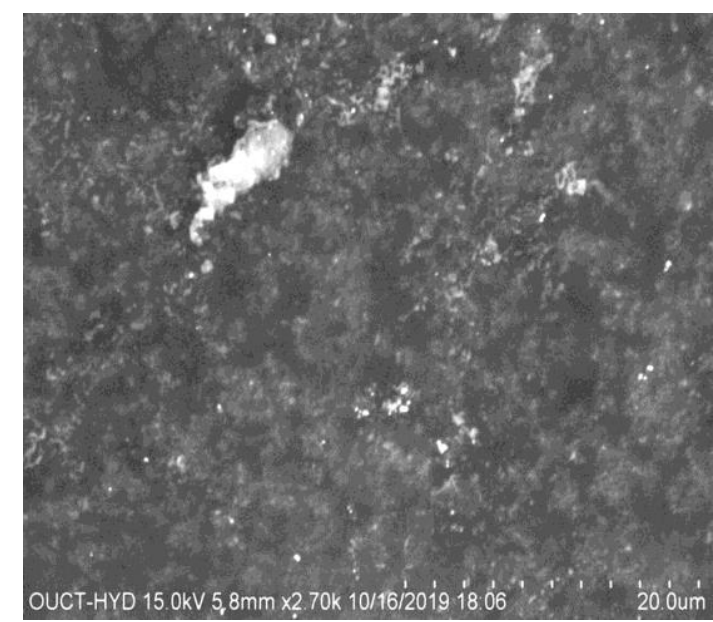

(a)

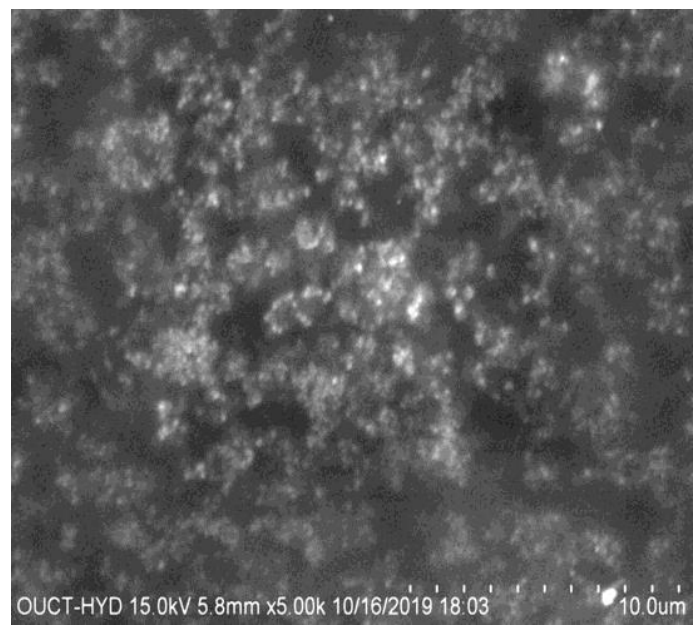

(b)

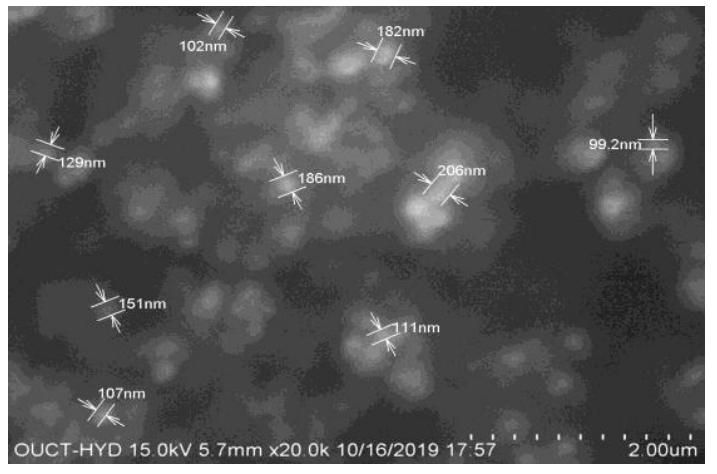

(c)

Figure $6(\mathrm{a}-\mathrm{c})$ : SEM images of the biosynthesized AgNPs at different magnifications

- Transmission Electron Microscopy

Morphological structure and distribution of biosynthesized silver nanoparticles were characterized at high magnifications done by Transmission Electron Microscopy (TEM). Figure 7 shows the well dispersed predominantly spherical shape of silver nanoparticles and it also confirms that the biosynthesized AgNPs were in nanosize i.e., it ranges from 5-200 nm. It is also quite obvious from the images that the AgNPs were capped with phytoconstituents of Achras sapota ethanolic leaf extract.

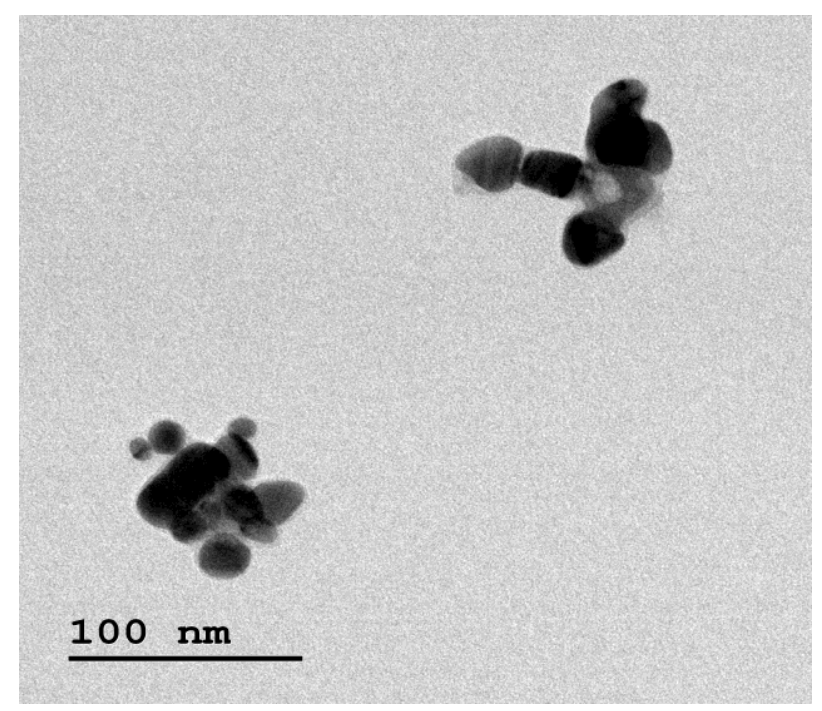

(a) 


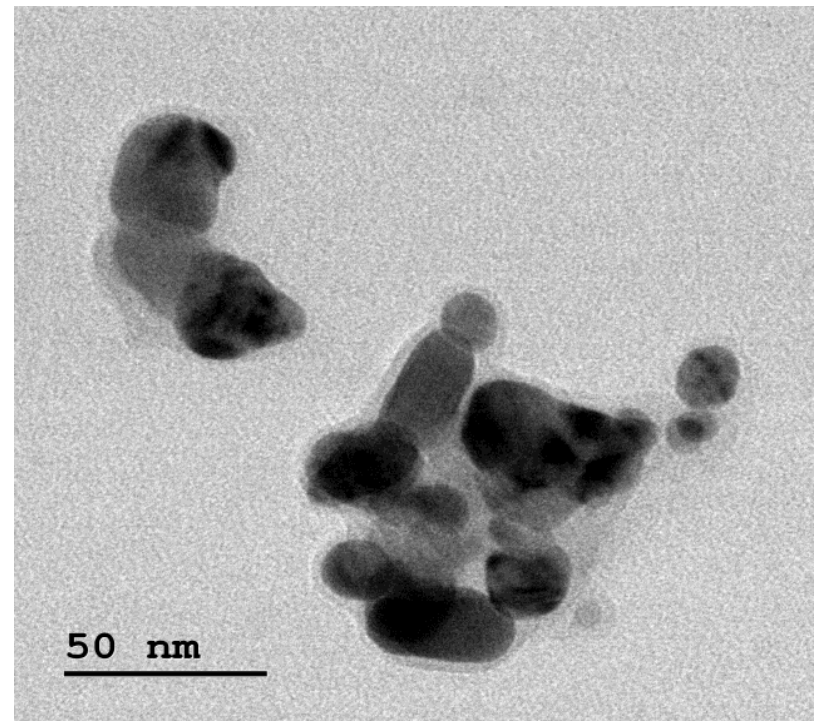

(b)

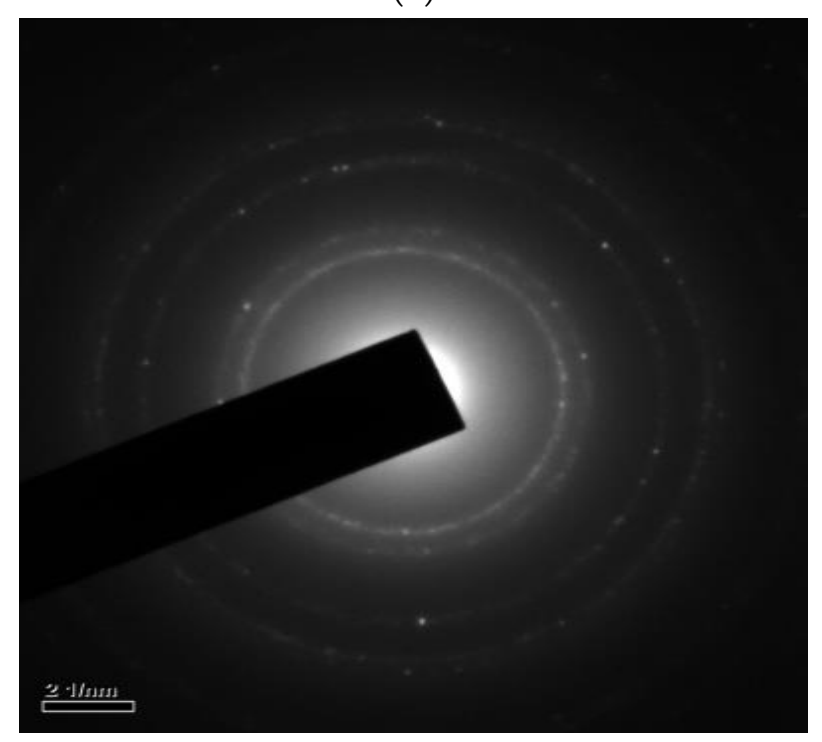

(c)

Fig 7 (a-b): TEM images of biosynthesized AgNPs prepared from the ethanolic leaf extract of Achras sapota at different magnification and (c) : SAED picture

3.5 Antimicrobial activity of the biosynthesized silver nanoparticles

- Preliminary test for antibacterial activity

The antibacterial activity of different concentrations of AgNPs was proved from the zone of inhibition (Figure 8) against gram negative (Escherichia coli, Pseudomonas aeruginosa) and gram positive microorganisms (Staphylococcus aureus and Lacto bacillus). Silver nanoparticles $(50 \mu \mathrm{g} / \mathrm{ml})$ showed a clear zone of inhibition in all the 4 plates. No zone of inhibition is observed in the vehicle control well which is in the middle of the plate which suggested that the antimicrobial activity was specifically due to silver nanoparticles.

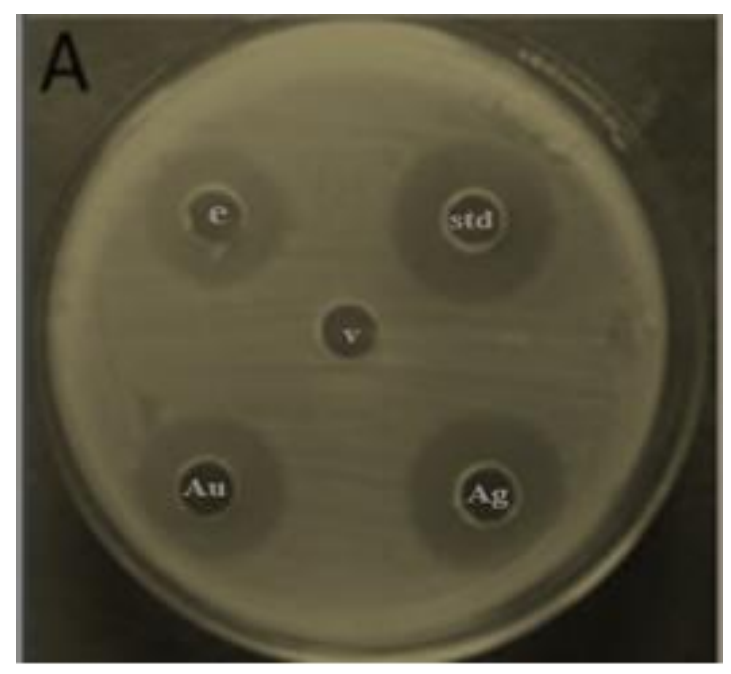

A. E. coli

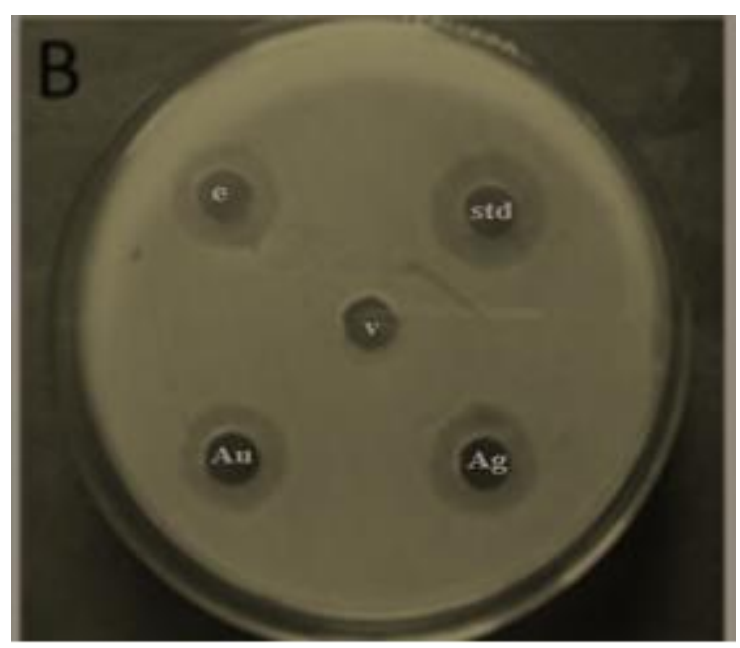

B. P. aeruginosa 


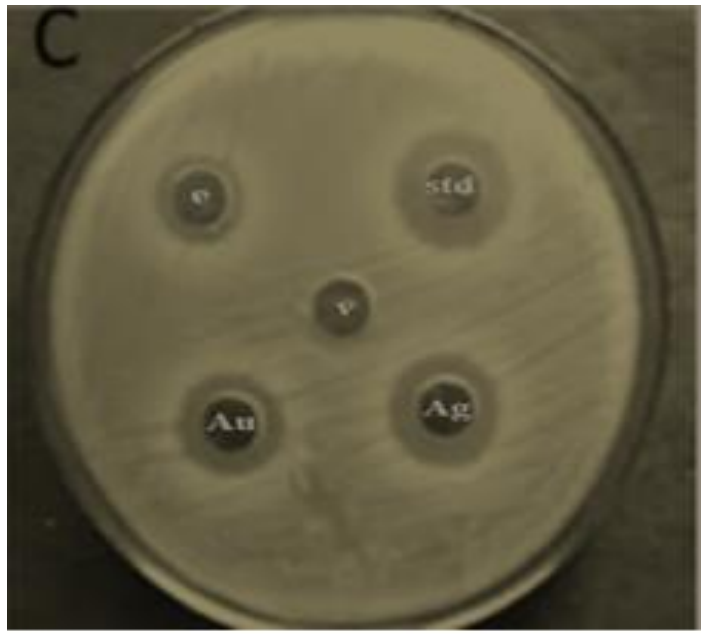

C. S. aureus

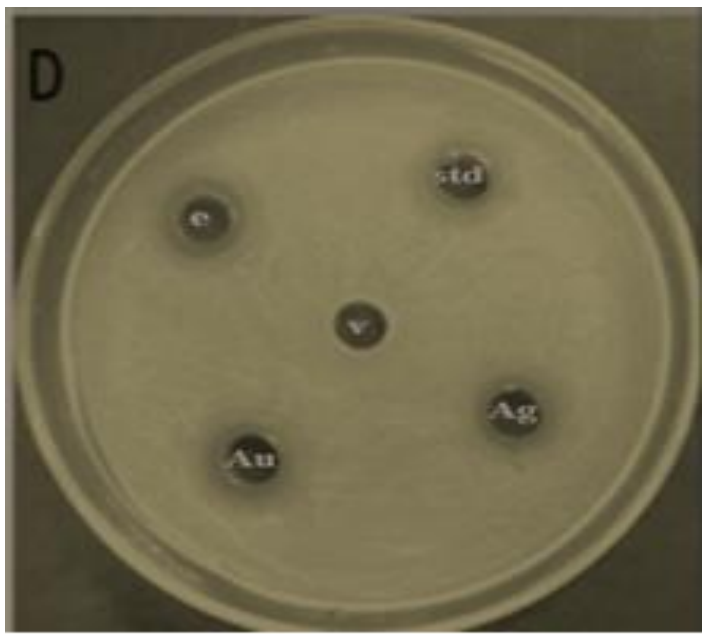

D. L. bacillus

Figure 8 (A-D): Zone of inhibition of AgNPs

- Evaluation of antibacterial effectiveness using Minimum Inhibitory Concentration method

To study the antimicrobial effectiveness of silver nanoparticles, a bacterial concentration of high CFU $(10 \% \mathrm{ml})$ were treated with varying concentration of silver nanoparticles from 0.25 to $50 \mu \mathrm{g} / \mathrm{ml}$. When the concentration of AgNPs was increased the bacterial concentration was found to decrease. At a concentration of $50 \mu \mathrm{g} / \mathrm{ml}$ of AgNPs, the growth of the microorganisms of gram negative (Escherichia coli, Pseudomonas aeruginosa) and gram positive microorganisms (Staphylococcus aureus and Lacto bacillus) was completely inhibited, which indicated that the minimum inhibitory concentration of AgNPs was $50 \mu \mathrm{g} / \mathrm{ml}$ (Figure 9-13).

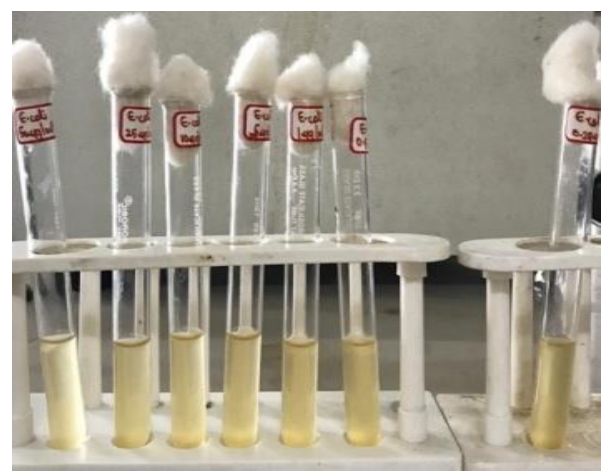

(a)

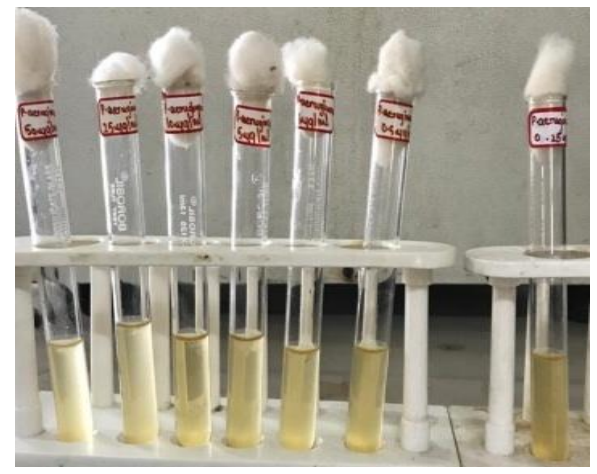

(b)

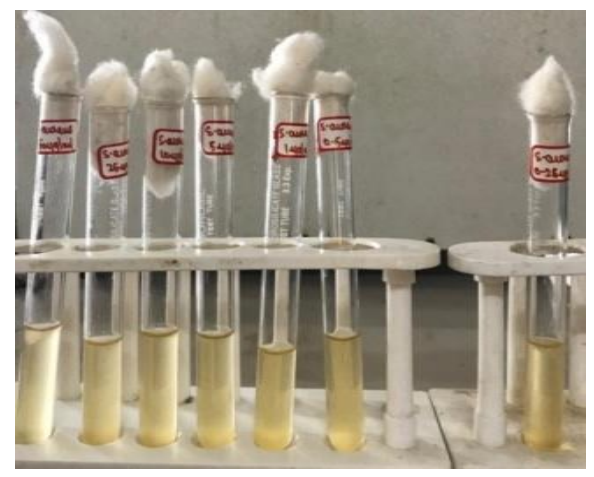

(c)

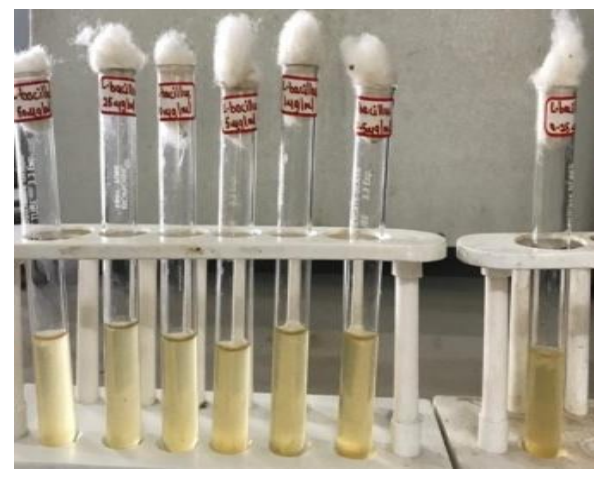

(d)

Figure 9 (a-d): Determination of MIC of AgNPs 
where $\mathrm{a}, \mathrm{b}, \mathrm{c}$ and $\mathrm{d}$ indicates different concentrations of E. coli, P. aeruginosa, S. aureus and L. bacillus respectively

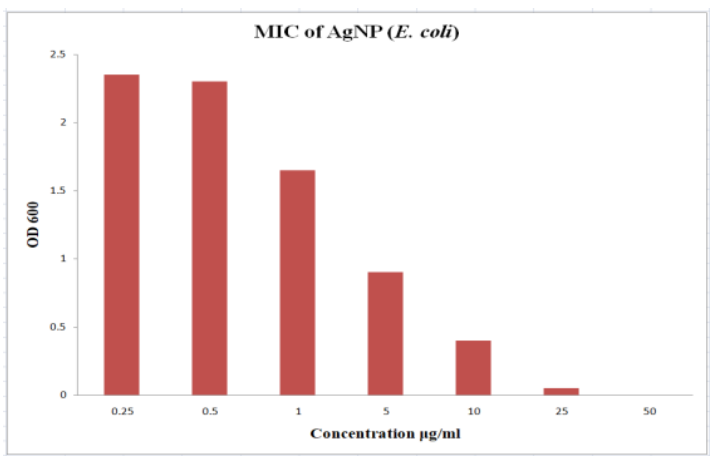

Figure 10: MIC of AgNPs on E. coli

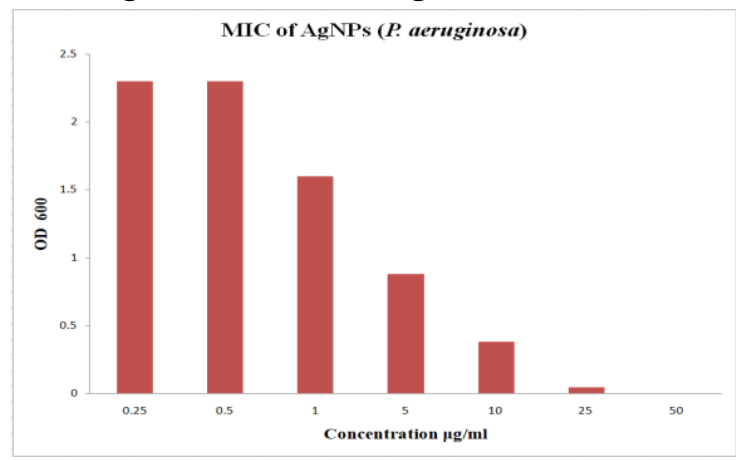

Figure 11: MIC of AgNPs on P. aeruginosa

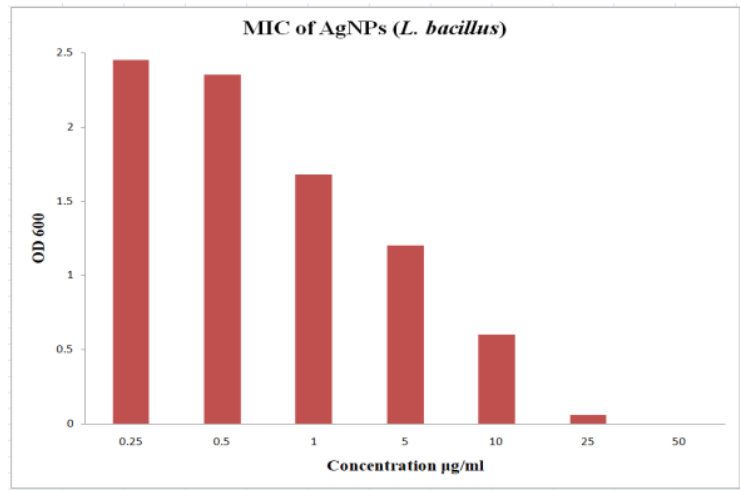

Figure 12: MIC of AgNPs on L. bacillus

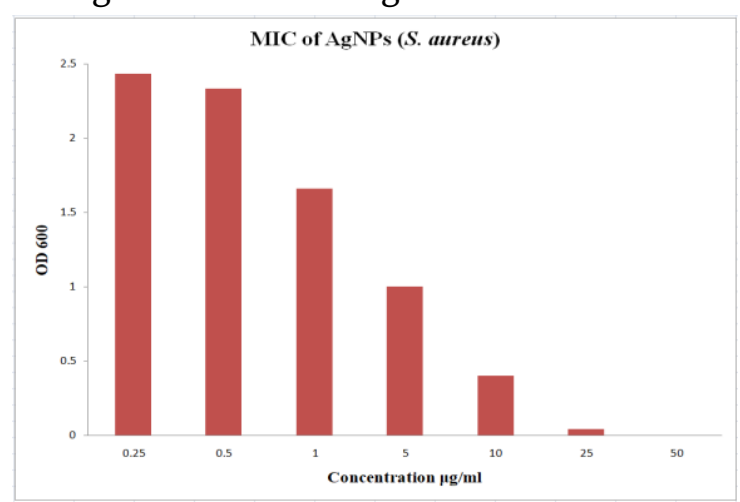

Figure 13: MIC of AgNPs on $S$. aureus
- Effect of AgNPs on bacterial growth

Growth rates and bacterial concentrations were determined by measuring OD at $600 \mathrm{~nm}$ at different time points i.e., from 1 to 6 hours (Figure 9). The slope of the bacterial growth curve continuously decreased with increasing silver nanoparticles concentration. This means that at low concentration of the nanoparticles, the growth of all the four i.e., Escherichia coli, Pseudomonas aeruginosa, Staphylococcus aureus and Lacto bacillus bacteria were delayed and at higher concentration, growth was completely inhibited. So it can be concluded that silver nanoparticles are bacteriostatic at low concentration and bactericidal at high concentration (Figure 14-17).
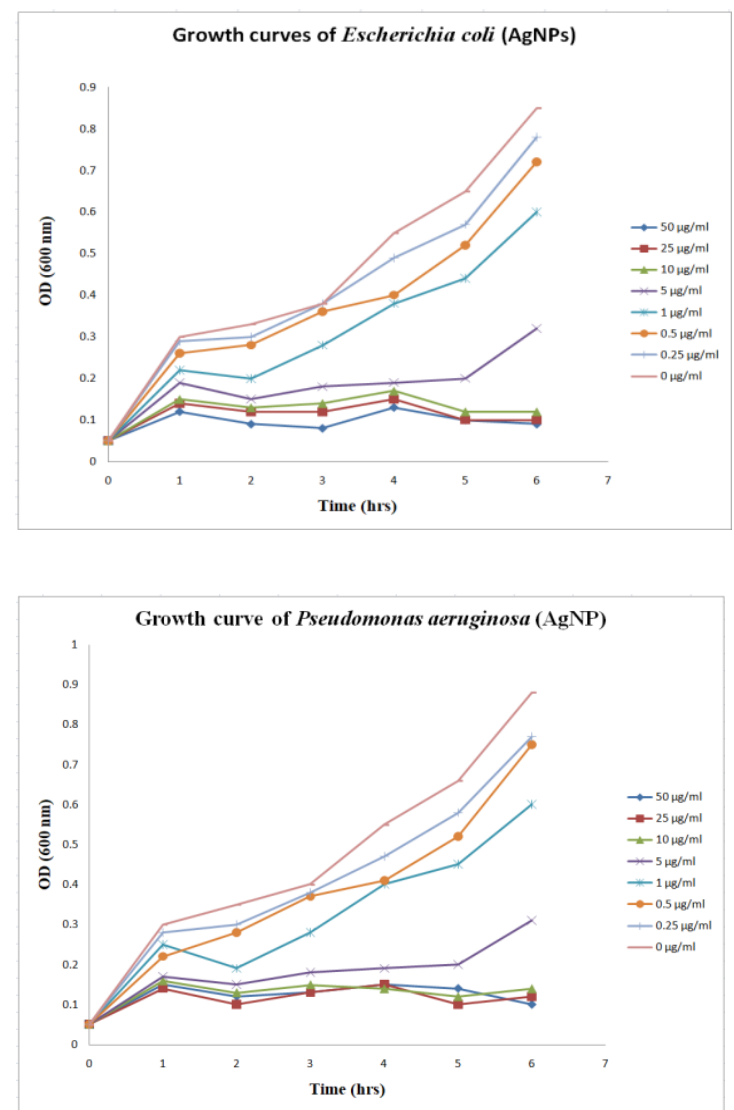

Figure 14 and 15: Growth curve of E. coli and $P$. aeruginosa using biosynthesized AgNPs as an antibacterial agent 


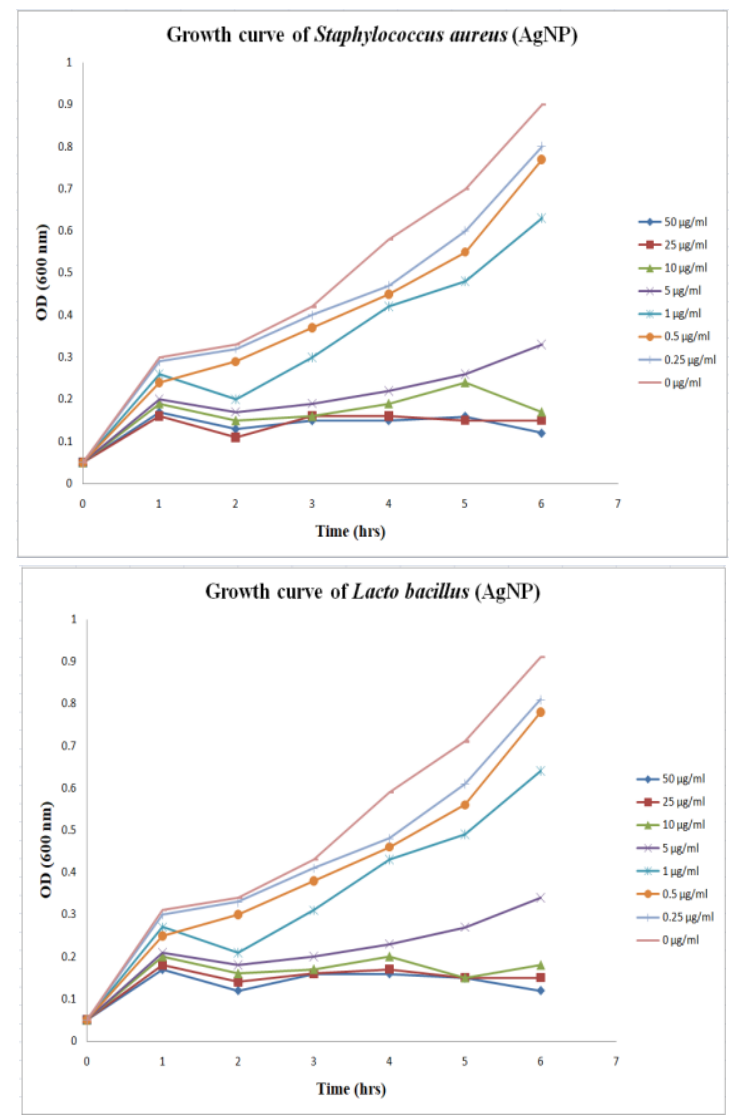

Figure 16 and 17: Growth curve of $S$. aureus and $L$. bacillus using biosynthesized AgNPs as an antibacterial agent

\section{IV.CONCLUSION}

A simple one-pot green synthesis of stable silver nanoparticles using the ethanolic leaf extract of Achras sapota L. at room temperature was reported in this study. Synthesis was found to be efficient in terms of reaction time as well as stability of the synthesized nanoparticles which exclude external stabilizers/reducing agents. It proves to be an ecofriendly, rapid green approach for the synthesis providing a cost effective and an efficient way for the synthesis of silver nanoparticles and it was also found out that the biosynthesized silver nanoparticles possess potent antimicrobial activity.

\section{REFERENCES}

[1]. Herlekar M, Barve S, Kumar R. Plant-mediated green synthesis of iron nanoparticles. Journal of Nanoparticles. 2014.

[2]. Srikar SK, Giri DD, Pal DB, Mishra PK, Upadhyay SN. Green synthesis of silver nanoparticles: a review. Green and Sustainable Chemistry. 2016; 6(01):34.

[3]. Ikram S. Synthesis of gold nanoparticles using plant extract: An overview. Archivos De Medicina. 2015; 1(1):5.

[4]. Lawrence AA, Prakash JT. A review on nanotechnology and plant mediated metal nanoparticles and it's applications. 2019.

[5]. Ahmed S, Ahmad M, Swami BL, Ikram S. A review on plants extract mediated synthesis of silver nanoparticles for antimicrobial applications: a green expertise. Journal of advanced research. 2016 Jan 1; 7(1):17-28.

[6]. Kokate CK, Practical Pharmacognosy. New Delhi; Vallabh Prakashan; 2010.

[7]. Pulok K Mukherjee, Quality Control of Herbal Drugs - an approach to evaluation of Botanicals. 1st ed. Business Horizons. 2008:247370.

[8]. Folorunso A, Akintelu S, Oyebamiji AK, Ajayi S, Abiola B, Abdusalam I, Morakinyo A. Biosynthesis, characterization and antimicrobial activity of gold nanoparticles from leaf extracts of Annona muricata. Journal of Nanostructure in Chemistry. 2019; 9(2):1117.

[9]. Aljabali AA, Akkam Y, Al Zoubi MS, AlBatayneh KM, Al-Trad B, Abo Alrob O, Alkilany AM, Benamara M, Evans DJ. Synthesis of gold nanoparticles using leaf extract of Ziziphus zizyphus and their antimicrobial activity. Nanomaterials. 2018; 8(3):174.

[10]. Maiti S, Krishnan D, Barman G, Ghosh SK, Laha JK. Antimicrobial activities of silver 
nanoparticles synthesized from Lycopersicon esculentum extract. Journal of analytical science and technology. 2014; 5(1):40.

[11]. Soliman H, Elsayed A, Dyaa A. Antimicrobial activity of silver nanoparticles biosynthesized by Rhodotorula sp. strain ATL72. Egyptian Journal of Basic and Applied Sciences. 2018; 5(3):228-33.

[12]. Novak JP, Brousseau LC, Vance FW, Johnson RC, Lemon BI, Hupp JT, Feldheim DL. Nonlinear optical properties of molecularly bridged gold nanoparticle arrays. Journal of the American Chemical Society. 2000; 122(48):12029-30.

\section{Cite this article as :}

Maphibanri Maring, Akila Elias, V. B. Narayanaswamy, "Biosynthesis and Characterisation of Silver Nanoparticles using Leaf Extract of Achras sapota 1. for its Antimicrobial Activity", International Journal of Scientific Research in Science and Technology (IJSRST), Online ISSN : 2395-602X, Print ISSN : 2395-6011, Volume 7 Issue 5, pp. 246-256, September-October 2020. Available at doi : https://doi.org/10.32628/IJSRST207548 Journal URL : http://ijsrst.com/IJSRST207548 